\title{
Injuries Related to Hiking with a Pack During National Outdoor Leadership School Courses: A Risk Factor Analysis
}

\author{
Matthew T. Hamonko, MD, MPH; Scott E. McIntosh, MD, MPH; Tod Schimelpfenig; Drew Leemon \\ From the Department of Surgery, Division of Emergency Medicine, University of Utah, Salt Lake City, UT (Drs Hamonko and McIntosh); \\ National Outdoor Leadership School, Lander, WY (Mr Schimelpfenig and Mr Leemon).
}

\begin{abstract}
Objectives.-To determine if packweight, anthropometry, and individual characteristics are related to acute musculoskeletal and soft tissue injuries while wearing backpacks on wilderness expeditions.

Methods.-This was a review of prospectively gathered data on participants and instructors enrolled in National Outdoor Leadership School Rocky Mountain hiking courses between March 2008 and October 2009. Packweight, height, body weight, age, and gender were collected. Individuals that suffered acute musculoskeletal and soft tissue injuries while hiking with a backpack were recorded and compared to individuals that did not suffer injuries. Logistic regression was used to determine which variables were significantly correlated with injuries. Odds ratios with associated confidence intervals and $p$-values are reported.

Results.-One thousand two hundred and one individuals were included in the final analysis. Twenty-six individuals of this population suffered reportable musculoskeletal and soft tissue injuries while hiking with a pack. None of the factors examined (packweight, height, body weight, age, gender, or packweight to body weight ratio) were significant in predicting acute injury.

Conclusions.-Based on our results, an individual's packweight, anthropometry, and individual characteristics neither increase nor decrease their risk of experiencing a musculoskeletal or soft tissue injury while hiking with a backpack. Other factors, including fitness, pretrip training, and footwear, should be examined to determine appropriate strategies to reduce significant musculoskeletal and soft tissue injuries on wilderness expeditions.
\end{abstract}

Key words: wilderness medicine, injury, packweight, backpack

\section{Introduction}

Interest in wilderness hiking has increased substantially in the past few decades, with trails such as the Appalachian Trail (AT) reporting an increase of several thousand hikers per year since the 1960s. ${ }^{1}$ Many hikers have also taken up the sport of ultralight backpacking. ${ }^{1}$ However, there is a paucity of data in the literature that explores the relationship between packweight and injury rates in hikers. Also, few data explore the association between the height, body weight, age, and gender of the backpacker and the odds of suffering a musculoskeletal or soft tissue injury.

Corresponding author: Matthew T. Hamonko, MD, MPH, P.O. Box 684344, Park City, UT 84068 (e-mail: matt.hamonko@gmail.com).
A cross-sectional study published in 2009 reported an association between packweight and the prevalence of paresthesias among long distance hikers on the AT and the Pacific Crest Trail (PCT). ${ }^{2}$ However, it reported no significant association between packweight and muscle or tendon injuries, joint problems, or fractures. ${ }^{2}$ Military studies also provide information regarding injury patterns and risk factors that can be extrapolated to recreational hikers. ${ }^{3-5}$

One study examining wilderness incidents reported many varied injuries during hiking and suggested that the correlation between packweight and injury should be further elucidated. ${ }^{6}$ Although the above studies attempted to describe backpack-related injuries and report risk factors for backpack-related injuries, the numbers of individuals in these studies were often relatively small, partially because 
Table 1. Descriptive characteristics of injured hikers and total hikers on National Outdoor Leadership School (NOLS) Rocky Mountain courses between March 2008 and October 2009

\begin{tabular}{|c|c|c|c|c|}
\hline \multirow[b]{2}{*}{ Characteristic } & \multicolumn{2}{|c|}{$\begin{array}{c}\text { Injured } \\
\text { population }\end{array}$} & \multicolumn{2}{|c|}{$\begin{array}{c}\text { Total } \\
\text { population }\end{array}$} \\
\hline & Mean & $S D$ & Mean & $S D$ \\
\hline Age (years) & 22.9 & 6.2 & 22.3 & 8.0 \\
\hline Height $(\mathrm{cm})$ & 172.6 & 10.3 & 175.0 & 9.2 \\
\hline Body weight (kg) & 68.1 & 12.0 & 69.3 & 11.6 \\
\hline Pack weight $(\mathrm{kg})$ & 23.5 & 4.4 & 22.4 & 3.9 \\
\hline
\end{tabular}

Injured population $n=26$; uninjured population $n=1175$.

of the difficulty in collecting data on hikers. We examined packweight, height, body weight, age, and gender and how these factors correlate with the incidence of musculoskeletal and soft tissue injuries while hiking with a backpack on wilderness expeditions conducted by the National Outdoor Leadership School (NOLS). NOLS is a wilderness education school that was started in $1965 .^{6}$ Approximately 3000 students enroll each year and participate in an average of 150,000 days of field activities annually. ${ }^{7}$ Identifying these risk factors may allow wilderness organizations and individuals to reduce the incidence of injuries on their backpacking expeditions.

\section{Methods}

We conducted a review of prospectively gathered data on packweight, height, and body weight that was collected from instructors and students participating in NOLS Rocky Mountain hiking courses from March 1, 2008 to October 3, 2009. Height and body weight were self-reported by the participants and instructors at the start of the expedition. Packweight was measured using a Hanson Model 9810 scale that was calibrated at the beginning of the NOLS season to within $2.2 \mathrm{~kg}$ of accuracy. Packweight was measured at the beginning of the course when students departed from the NOLS base and included the weight of $1 \mathrm{~L}$ of water contained in the pack $(1 \mathrm{~L}$ water $=1 \mathrm{~kg})$.

NOLS maintains a database of all reportable medical incidents that occur during their courses. To be considered a reportable incident, an injury or illness must require more than simple first aid, need follow-up care or the use of prescription medications, interfere with active participation for 12 hours beginning the next day (lost-day case), require evacuation, or be considered a near miss (the incident could have resulted in an injury or illness but did not, eg, a "close call"). Instructors in the field report incidences using special report forms. ${ }^{6}$
For the purposes of our study, an "injury" was defined as an acute musculoskeletal or soft tissue injury that was sustained while hiking with a pack. This definition also included cases in which an individual suffered a similar injury in the past, but the current injury was acute ("acute on chronic"). If the injury met criteria for a reportable incident, additional data were collected which described the incident in greater detail. Evacuation was defined as a situation that required a participant to leave the field.

Logistic regression was used to determine if a relationship existed between the independent variables and an injury that occurred while hiking with a pack. Odds ratios, including their respective confidence intervals and $p$-values, were reported for each independent variable. A $p$-value less than 0.05 was considered statistically significant. Descriptive statistics and logistic regression were performed using SPSS (v.16, SPSS, Inc., Chicago, IL). This study was reviewed and approved by the University of Utah Institutional Review Board. Informed consent was waived.

\section{Results}

Over the study period, NOLS collected data on 1283 individuals who took part in NOLS Rocky Mountain hiking courses. Eighty-two of the initial 1283 individuals were excluded from the final analysis because of incomplete data. Three of the 82 excluded individuals suffered injuries. Of the 3 excluded individuals, 2 were male and 1 was female, the average age was 40.3 years, and the average packweight was $15.0 \mathrm{~kg}$.

The majority of included participants were male, representing $67.9 \%$ of the population. Twenty-six individuals (2.2\%) suffered an acute musculoskeletal injury while hiking with a pack. Descriptive characteristics of the injured and study population are included in Table 1 . The weight of the packs ranged from 9.1 to $38.6 \mathrm{~kg}$. The injured population was $53.8 \%$ male and $46.2 \%$ female. Of the 26 injured

Table 2. Anatomical location of injuries that occurred while hiking with a backpack on National Outdoor Leadership School (NOLS) Rocky Mountain courses between March 2008 and October 2009

\begin{tabular}{lrr}
\hline \multicolumn{1}{c}{ Location } & Number & Percentage \\
\hline Knee & 13 & 44.8 \\
Ankle & 10 & 34.5 \\
Back & 2 & 6.9 \\
Leg (nonspecific) & 2 & 6.9 \\
Foot & 1 & 3.4 \\
Hand & 1 & 3.4 \\
Total & 29 & 100.0 \\
\hline
\end{tabular}


Table 3. Contributing factors associated with injuries that occurred while hiking with a backpack on National Outdoor Leadership School (NOLS) Rocky Mountain courses between March 2008 and October 2009

\begin{tabular}{lrc}
\hline \multicolumn{1}{c}{ Contributing factor } & Number & Percentage \\
\hline Nonspecific overuse/exertion & 14 & 48.3 \\
Fall & 10 & 34.5 \\
Donning backpack & 1 & 3.4 \\
Blunt trauma $^{a}$ & 1 & 3.4 \\
Penetrating trauma $^{b}$ & 1 & 3.4 \\
Kneeling $_{\text {No MOI }}$ specified $^{\text {Total }}$ & 1 & 3.4 \\
\end{tabular}

\footnotetext{
${ }^{a}$ The individual pulled a rock down which struck him on the hand.

${ }^{b}$ The individual fell back on a large piece of wood that impaled her posterior thigh.

${ }^{c} \mathrm{MOI}=$ mechanism of injury.
}

individuals, 21 of the injuries were acute and 5 were acute on chronic. Twenty of the injured individuals required evacuation, and 6 did not. Details regarding the anatomic location of injuries are included in Table 2. Twenty-two $(84.6 \%)$ of the injuries were sustained to the lower extremity. The factors related to the injuries are shown in Table 3. There was no specific contributing factor recorded in the majority of injuries; however, when a contributing factor was listed, falls were most common.

Univariate logistic regression analysis revealed no significant relationship between height, body weight, packweight, packweight to body weight ratio, age, or gender and injuries that occurred while hiking with a pack (Table 4). Packweight to body weight ratio trended towards significance on univariate analysis $(p=.09)$, but ceased to trend in this direction on the multivariate analysis. Other variables remained nonsignificant in the multivariate analysis.

\section{Discussion}

Our study reports no significant relationship between height, body weight, packweight, age, gender, and packweight to body weight ratio and the risk of significant musculoskeletal or soft tissue injuries while hiking with a backpack. Out of a population of 1283 individuals, there was a relatively low incidence of reported injuries. The majority of injuries were to the ankles and the knees, and the most common mechanism of injury was a fall.

Based on the analysis of our data, the risk factors for injury while hiking with a backpack remain elusive. Our study evaluated several potential risk factors, but failed to find any that were significantly correlated with injury. As was suggested in the paper by Anderson et al, ${ }^{1}$ many hikers believe that lighter packs prevent injury. However, our results do not support that claim; neither the independent weight of the pack nor the packweight to body ratio appeared to correlate with injury.

The other potential contributors to injury are many. Footwear or clothing may have played a role. The weather and the distance of the hike may also have been a factor. Additionally, the physical fitness and hiking experience of the individual may also be significant. If these parameters could be evaluated, perhaps a true risk factor would emerge. However, the logistics of collecting and quantifying physical fitness and experience may prove difficult. Collecting information on weather, footwear, and clothing may also prove to be impractical.

Although we were unable to determine significant risk factors, we were able to collect descriptive data regarding the circumstances of the injuries and the body parts injured. Two important finding are that most injuries were to the knees and ankles and that most injuries were secondary to falls or overuse when a mechanism was recorded. In addition to injuries of the knee and ankle, other anatomical locations were injured, but to a much lesser degree. These findings are consistent with previous studies published using information from NOLS expeditions. ${ }^{6-8}$ However, they do not correlate with military studies. $^{3-5}$

A search of the literature reveals several military studies that have evaluated injury patterns in soldiers after marches with a pack and the associated risk factors. ${ }^{3-5}$ Reynolds et al conducted a study of 218 United States infantry soldiers carrying an average weight of $47 \pm 5 \mathrm{~kg}$ for $161 \mathrm{~km} .{ }^{5}$ They reported that blisters and unspecified foot pain were the most common injuries reported. They also determined that younger age $(<20$ years $)$ was an independent risk factor for both blisters and musculoskeletal injuries and that height was not a significant risk factor for either of these conditions. ${ }^{5}$ Although our study

Table 4. Univariate analysis to evaluate the relationship between selected variables and suffering a musculoskeletal or soft tissue injury while hiking with a backpack on National Outdoor Leadership School (NOLS) Rocky Mountain courses between March 2008 and October 2009

\begin{tabular}{lccc}
\hline \multicolumn{1}{c}{ Variable } & OR & p-value & 95\% CI \\
\hline Packweight $(\mathrm{kg})$ & 1.07 & 0.17 & $0.97,1.17$ \\
Height $(\mathrm{cm})$ & 0.97 & 0.20 & $0.93,1.01$ \\
Body weight $(\mathrm{kg})$ & 0.99 & 0.59 & $0.96,1.03$ \\
Packweight/body weight ratio & 1.05 & 0.09 & $0.99,1.11$ \\
Age & 1.01 & 0.67 & $0.97,1.06$ \\
Male gender & 1.84 & 0.13 & $0.84,4.02$ \\
\hline
\end{tabular}


does corroborate their findings, in regards to height, our results do not corroborate their findings in regards to age.

Knapik et al suggested that increased packweights lead to an increased incidence of blisters. ${ }^{4}$ A study of 15 male soldiers carrying packs of various weights found that soldiers marching with a $61 \mathrm{~kg}$ pack had a significantly higher rate of blisters than soldiers marching with a 34 or $48 \mathrm{~kg}$ pack. ${ }^{4}$ Although blisters may occur during NOLS trips, they are not reported unless they meet the aforementioned criteria for a significant reportable injury; therefore, our study did not evaluate the correlation between packweight and blister formation. The military studies mentioned above were relatively small study populations, and it may be difficult to extrapolate these results to the civilian population. Importance of blister prevention may also have been a confounding factor. NOLS has a very low threshold for intervention to prevent blisters. Therefore, blisters that did occur during NOLS trips may have been treated earlier before they reached a level of severity that required reporting by NOLS staff.

Civilian studies are limited to a small number of published papers. A case control and a cross-sectional study, which both evaluated civilian long-distance hikers, found no association between packweight and the rate of injuries. ${ }^{1}$ Also, 3 previously published studies which analyzed NOLS expeditions have reported injury patterns during NOLS courses, but did not statistically evaluate the risk factors for these injuries. ${ }^{6-8}$

Gentile et al reviewed illnesses and injuries that occurred during NOLS courses between September 1984 and September 1989. ${ }^{7}$ They concluded that sprains, strains, and soft tissue injuries were the most common and that the ankle and the knee were the most commonly injured anatomical locations. A study by Leemon and Schimelpfenig analyzed NOLS expeditions between September 1998 and August 2002. ${ }^{6}$ These authors also concluded that sprains, strains, and soft tissue injuries were most common, And, consistent with the previous study and ours, knees and ankles were the most common locations of athletic injuries. In addition, this study by Leemon and Schimelpfenig reported that falls and overuse were the most common contributing factors to injuries, which is also consistent with our findings. A final study by McIntosh et al reviewed NOLS expeditions between September 2002 and August 2005. ${ }^{8}$ Once again, athletic and soft tissues injuries were found to be the most common type of injury. Hiking was the most common activity during which participants were injured. The results of our study closely compare to the results of these 3 previous studies, suggesting that certain injury patterns during NOLS courses have remained consistent over the past several years. However, different patterns emerge on review of the other existing literature on hiking and backpack related injuries. Multiple factors may contribute to this discrepancy, such as the fitness of the individual, type of terrain, weather, duration of the hike, and equipment used.

NOLS attempts to reduce injury rates through course design and precourse fitness training. Courses are designed so that physical exertion begins gradually, with an emphasis on warming-up and stretching before hiking and strenuous activities. Students are taught how to hike on rugged and uneven terrain and that it is acceptable to ask for assistance when picking up and putting on packs. Students are also advised to prepare physically for their NOLS course, based on specific recommendations.

NOLS also takes measures to reduce the weight carried by participants, based in part on the assumption that reduced packweight correlates with a reduced risk of injury. Our study does not support the efficacy of this strategy as a preventative measure. However, because of strongly held beliefs that packweight is correlated with injury rates, and the fact that our study is the only one to date that does not support this hypothesis, further research will be necessary to confirm the results of our data analysis and justify policy change. Our study highlights the need for further research in this area. At this time, the NOLS injury prevention strategy will continue to include packweight reduction both for student comfort and because of the continued belief that health and packweight are significantly correlated. Packweight may not be a significant risk factor for injury; however, packweight may impact the comfort and enjoyment of the hiker.

Our study did not evaluate other factors that are affected by packweight, such as comfort and the distance traveled; however, our results suggest that reducing packweight is not the "magic bullet" for hiking injury prevention. We should look further to understand the factors that contribute to injury. Education, course design, and precourse training may be more important. Although NOLS recommends conditioning prior to their courses, participants may not adhere to these recommendations, and, therefore, not be in appropriate physical condition when they arrive for their course. Additional education could also be provided regarding hiking on challenging terrain. Increased course planning may reduce injury rates, in particular, by avoiding terrain that may predispose to knee and ankle injuries. However, to our knowledge, there are no peer-reviewed studies that specify such terrain. Further studies will be necessary to determine what type of terrain is most likely to contribute to injuries and if the current interventions, such as precourse conditioning, have a significant impact on injury rates. These studies should also focus on additional variables, such as 
footwear, weather conditions, and level of physical fitness and attempt to collect more cases to increase the number included in the final statistical analysis.

\section{Limitations}

Our study was limited by multiple factors. The weight of each participant's pack was measured at the beginning of the NOLS trip but not during the trip or at the time of their injury. Therefore, a discrepancy between the weight of the pack on the day of injury and the initial recorded weight could have existed. This difference may have been secondary to the equipment carried and/or the food and water carried at the time of injury. Relatively few injuries were recorded. The identification and diagnosis of injuries during the NOLS courses was based on the assessment of an instructor with medical training at the level of a wilderness first responder or wilderness emergency medical technician. With this level of medical training and without imaging studies, it is possible that some of the types and severity of injury may have been misclassified and the need for evacuation incorrectly assessed.

Thirty-nine of the participants during the study period were enrolled in a "light and fast backpacking" course that utilized lighter weight backpacks. Data were missing from 17 of the 39 participants involved in this course, however, and it was not feasible to determine if the design of this course statistically affected injury rates. Height and/or weight data were also missing from 3 of the individuals in the injured population. Age, gender, and packweight data were available for these 3 individuals. Consistent with the included data, approximately two-thirds of these individuals were male. However, the age of the excluded individuals was greater and the packweight was less when compared to these respective values in the included injured population. It is possible that these individuals may have skewed the results, given the fact that the injured population was relatively small.

If more injuries occurred or if data were collected over a longer period of time, perhaps significant differences may have been detected between injured and uninjured individuals. Our study design did not allow us to correlate the distance hiked to the rate of injury. In addition to the distance hiked, we also had no record of the weather conditions that may have played a role. NOLS instructors followed an established protocol to determine if an individual had suffered a recordable injury. If the instructors were not aware an injury had occurred (eg, the injured person did not notify his or her instructor), then those cases would have been missed. If additional parameters were collected for each individual, such as clothing type, footwear, or physical fitness level, perhaps a significant correlation may have been found. Finally, our study population contained young adults, but no one under the age of 13; therefore, our results cannot be extrapolated to the young pediatric population.

\section{Conclusion}

Significant musculoskeletal and soft tissue injuries occur with a relatively low incidence while hiking with a pack during NOLS Rocky Mountain courses. The injuries that do occur are most commonly to the ankle and knee and are secondary to falls. Our study did not find any significant risk or protective factors for the injuries that did occur. Height, body weight, packweight, age, gender, and the packweight to body weight ratio do not appear to predict whether or not an individual will experience an injury. Further studies are needed to elucidate the specific risk factors for these injuries so that the appropriate preventative measures can be taken.

\section{Acknowledgments}

Two of the authors (Mr Schimelpfenig and Mr Leemon) are employed by the National Outdoor Leadership School (NOLS).

\section{References}

1. Anderson LS, Rebholz CM, White LF, et al. The impact of footwear and packweight on injury and illness among longdistance hikers. Wilderness Environ Med. 2009;20: 250-256.

2. Boulware DR. Backpacking-induced parethesias. Wilderness Environ Med. 2003;14:161-166.

3. Knapik J, Reynolds K, Staab J, Vogel JA, Jones B. Injuries associated with strenuous road marching. Milit Med. 1992; 157:64-67.

4. Knapik JJ, Ang P, Meiselman H, et al. Soldier performance and strenuous road marching: influence of load mass and load distribution. Milit Med. 1997;162:62-67.

5. Reynolds KL, White JS, Knapik JJ, Witt CE, Amoroso PJ. Injuries and risk factors in a 100-mile $(161-\mathrm{km})$ infantry road march. Prev Med. 1999;28:167-173.

6. Leemon D, Schimelpfenig T. Wilderness injury, illness, and evacuation: National Outdoor Leadership School's incident profiles, 1999-2002. Wilderness Environ Med. 2003;14: 174-182.

7. Gentile DA, Morris JA, Schimelpfenig T, Bass SM, Auerbach PS. Wilderness injuries and illnesses. Ann Emerg Med. 1992;21:853-861.

8. McIntosh SE, Leemon D, Visitacion J, Schimelpfenig T, Fosnocht D. Medical incidents and evacuations on wilderness expeditions. Wilderness Environ Med. 2007;18: 298-304. 